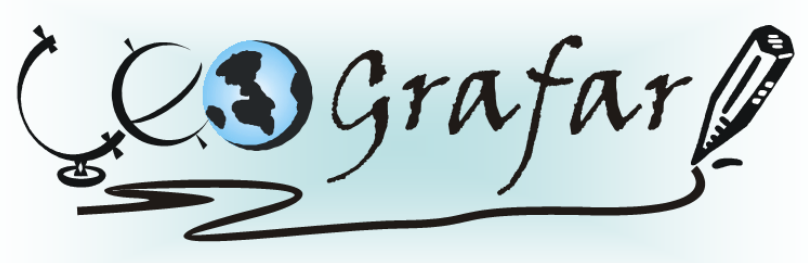

Revista Eletrônica do Programa de Pós-Graduação em Geografia - UFPR

\title{
OS ASPECTOS ETNOBOTÂNICOS DA COPAÍBA
}

\author{
JÚLIO CARDOSO ROSA \\ ANGELA Ma. DA SILVA GOMES
}

\begin{abstract}
Resumo: O objetivo deste trabalho é resgatar a importância da relação homem e natureza, desde o momento da sua utilização como meio de sobrevivência. O método utilizado neste trabalho foi pesquisar de forma criteriosa os dados culturais de diferentes saberes tradicionais relativo a copaíba. Interligando os seus saberes e significações, através de bibliografias, documentos acadêmicos e crônicas relativo a etnobotânica da copaíba. A Copaíba é uma espécie vegetal, Copaífera que pertence à família Leguminosae, sub-família Caesalpinoideae. No Brasil, Colômbia, Peru e Venezuela, existem 30 (trinta) espécies americanas e nos países da África, 04 (quatro) africanas. No Brasil ocorrem 16 espécies autóctones. Todas as variedades produzem uma resina, chamada óleo de copaíba, obtidas por incisão no tronco. Por isso, a árvore é conhecida como "pau-de-óleo", "óleo branco" e "árvore do óleo diesel". Mas a designação mais utilizada é copaíba. As florestas tropicais das Américas Central e do Sul são as mais atingidas pelo desmatamento, juntamente com as formações savânicas como é o caso do Cerrado. As causas dessa redução da cobertura vegetal, incluindo a copaíba se devem a exploração florestal intensiva para produção de carvão vegetal para abastecer a indústria siderúrgica. Em Minas Gerais muitas das áreas desmatadas foram ocupadas pelo reflorestamento do eucalipto e pinos. O óleo extraído da copaíba é utilizado na cicatrização de cortes na pele do homem e dos animais, como combustível nas lamparinas, na calafetação do casco de pequenas embarcações ribeirinhas e até mesmo marítimas pelos nossos colonizadores, portugueses e espanhóis. Portanto, os usos tradicionais da copaíba datam de tempos anteriores ao período colonial, refletindo o aporte do conhecimento produzido por etnias indígenas, africanas e comunidades rurais (Salvador, 1627). Contextualizar o uso da copaíba, requer políticas sócio-ambientais favoráveis ao extrativismo local, opondo-se a questão das patentes e da biopirataria.
\end{abstract}

\section{ASPECTS OF THE ETHNOBOTANY COPAIBA}

\begin{abstract}
The goal is to rescue the importance of the link man and nature, from the time of its use as a means of survival. The method used in this study was to investigate in a critical data from different cultural traditional knowledge on Copaiba. Linking their knowledge and meanings, through bibliographies, and scholarly papers on the ethnobotany of chronic Copaiba. The Copaiba is a plant species, Copaifera which belongs to the family Leguminosae, sub-family Caesalpinoideae. In Brazil, Colombia, Peru and Venezuela, there are 30 (thirty) species in the U.S. and countries in Africa, 04 (four) in Africa. In Brazil are 16 native species. All varieties produce a resin, called Copaiba oil, obtained by incising the trunk. Therefore, the tree is known as "pau-d'oil", "white oil" and "Tree of diesel fuel." But the term is used more Copaiba. The tropical forests of Central and South America are the most affected by deforestation, along with the savanna formations such as the Cerrado. The causes of the reduction of vegetation cover, including copaiba are due to intensive logging for charcoal production to supply the steel industry. In Minas Gerais many of deforested areas were occupied by the reforestation of eucalyptus and pins. The oil extracted from the Copaiba is used in the healing of cuts in the skin of humans and animals, as fuel in lamps in caulking the hull of small boats and even coastal shipping by our colonizers, Portuguese and Spanish. Therefore, the traditional practices of Copaiba times prior to the date from the colonial period, reflecting the contribution of the knowledge produced by indigenous peoples, African and rural communities (Salvador, 1627). Contextualise the use of Copaiba, requires socio-political environment favorable to the extraction site, objecting to the issue of patenting and biopiracy.
\end{abstract}




\section{INTRODUÇÃO}

A etnobotânica desponta como o campo interdisciplinar que compreende o estudo e interpretação do conhecimento, significação cultural, manejo e usos tradicionais dos elementos da flora (CABALLERO, 1979). Segundo Barrera (1979), os estudos vão além do que pode pretender a investigação botânica, uma vez que suas metas se concentram em pontos fundamentais que é a significação ou o valor das plantas em determinada comunidade humana. Dentre a diversificada fonte que a flora fornece para a aplicação do ser humano, o trabalho descreve a importância da copaíba no universo da etnobotânica.

Desde a ocupação dos portugueses, o Brasil vem enfrentando queima de áreas de cultivo e pastagens de vegetação original. O aumento do desmatamento com o intuito de facilitar a ocupação humana e conseqüentemente a especulação imobiliária, juntamente com a modernização da agricultura, ao longo dos anos, levou extinção de várias espécies vegetais e animais e erosão mais acentuada do solo. As florestas tropicais das Américas Central e do Sul são as mais atingidas pelo desmatamento, juntamente com as formações savânicas como é o caso do Cerrado. As causas dessa redução da cobertura vegetal e portanto da copaíba se devem a exploração florestal intensiva para produção de carvão vegetal para abastecer a indústria siderúrgica. Em Minas Gerais muitas das áreas desmatadas foram ocupadas pelo reflorestamento do eucalipto e pinos. Essas atividades florestais movimentam bilhões de dólares por ano e geraram impactos sócio-ambientais significativos. Segundo diversos autores a modernização da agricultura, nesse caso da silvicultura ${ }^{1}$ moderna, reduziram a biodiversidade e afetaram a diversidade cultural e portanto o modo de vida de comunidades tradicionais. Esta conjuntura traduz a dificuldade hoje das populações tradicionais ao acesso as matérias primas para sobrevivência através do extrativismo vegetal.

A Copaíba é uma das espécies que possui estudos ligados à ciência a etnobotânica, aos saberes tradicionais entrelaçados pelo conhecimento cultural e social, instrumentos fundamentais para uma leitura mais complexa da relação sociedade/natureza. O óleo extraído da copaíba é utilizado na cicatrização de cortes na pele do homem e dos animais, na iluminação sendo usado como combustível de lamparinas, na calafetação do casco de

\footnotetext{
${ }^{1}$ Silvicultura: ciência que se dedica ao estudo das árvores e formações vegetais, em especial ao: plantio e reprodução de vegetal, manejo florestal, fruticultura e cultivo de espécies arbórea em geral. A silvicultura comercial compreende segundo Vandana Shiva (2002) um ramo da ciência florestal moderna inserido na lógica capitalista que reduziu as florestas a fator de produção e lucro, através de monoculturas de árvores, como o caso do plantio do eucalipto e exploração ilimitada de florestas nativas, atendendo aos interesses mercadológicos.
} 
pequenas embarcações ribeirinhas e até mesmo marítimas pelos nossos colonizadores, portugueses e espanhóis. Os usos tradicionais da copaíba datam de tempos anteriores ao período colonial, refletindo o aporte do conhecimento produzido por etnias indígenas, africanas e comunidades rurais (SALVADOR, 1627).

Este trabalho tem como objetivo pesquisar de forma integrada, os saberes tradicionais da copaíba, por diferentes culturas. Interligando os grupos étnicos, os usos da flora local e as significações que estes deram à copaíba, através de bibliografias e documentos. Associado a isto descreve-se essa planta, popularmente denominada copaíba com áreas de ocorrência desde a África, a América do Sul (Brasil), a América Central e nas Antilhas. Busca-se assim, na literatura relativa à etnobotânica, resgatar histórias e mitos construídos por diferentes povos e civilizações em relação a planta copaíba.

A finalidade deste trabalho, é analisar e destacar a importância da flora brasileira, em especial, para os grupos étnicos ou populações tradicionais, que dependem desta como meio de sobrevivência sustentável.

\section{SABER CULTURAL: ETNOBOTÂNICA DA COPAÍBA}

A etnobotânica compreende o estudo e a interpretação do conhecimento, significação cultural, manejo e usos tradicionais dos elementos da flora. Como agentes da etnobotânica, os povos tradicionais desempenham na exploração dos ambientes naturais o papel de informar de maneira visível as diferentes formas de manejo executadas no seu cotidiano e usufruindo da exploração enquanto forma de sustentação. É preciso resgatar os saberes tradicionais que a população detém sobre o uso de recursos naturais, diante da marcha da urbanização e das possíveis influências da aculturação.

O conhecimento etnobotânico, portanto implica em analisar os saberes e práticas tradicionais étnicas da natureza. A abordagem da etnobotânica requer distinguir alguns núcleos de reflexão:

O fundamento das etnociências; as temáticas e o desenvolvimentos das etnociênçias; o diálogo (as correspondências, analogias e relações) entre saberes, ciências e tecnologias indígenas com as etnociências; as estratégias de apropriações da natureza e da cultura, dos saberes e conhecimentos, das ciências e tecnologias, das comunidades indígenas e camponesas, e a definição de novas formas de etnodesenvolvimento e um programa de pesquisa para as etnociências que pudesse 
fundamentar, orientar e apoiar a construção de uma racionalidade ambiental a partir dos saberes locais. (LEFF, 1998, p. 265)

Tudo isso nos leva a esmiuçar a complexa relação entre os saberes indígenas, africanos e tradicionais nos diferentes níveis, a partir das próprias comunidades na organização interna, buscando-se os sentidos culturais e as aplicações práticas de seus saberes para a reflexão sobre os saberes tradicionais. A etnociência interroga os saberes tradicionais, os não codificados pelas normas da racionalidade científica moderna.

Portanto segundo Enrique Leff (1998), a etnociência reconhece as questões físicas e climáticas dos ecossistemas, entretanto vê sua limitação quando ausente de seus objetos de estudos, as particularidades étnicas em relação a utilização da natureza que diferentes povos fizeram e possuem sobre cada cultura local. Reconhece assim, as formas e as funções adaptativas ao meio e de reprodução cultural, isto é, a adaptação dos seres humanos no decorrer dos tempos, em determinada região, em decorrência das questões físicas, climáticas e culturais, os quais são fatores determinantes nas diferenças de uso de cada comunidade étnica e sua apropriação do meio.

O homem e a natureza se entrelaçam desde o primeiro momento em que ele a utilizou para sua sobrevivência e começou a cultivá-la como fonte de sobrevivência e forma física e juntamente vieram suas crenças, histórias e mitos.

Neste sentido, a etnociência articula os diferentes níveis de construção de saberes.

[...a questionar a fundamentação de seus objetos científicos, seus métodos de estudo e seus programas de pesquisa. Esta reflexão epistemológica sobre as etnociências não deverá circunscrever-se às disciplinas etnobotânicas; deve incluir também os desenvolvimentos da antropologia e da etnologia, enquanto se referem - de maneira direta, colateral ou complementar - ao processo de construção dos saberes dos povos indígenas sobre a natureza. Esta é a única maneira de ter o mapa completo da constituição dos objetos de conhecimento e das abordagens metodológicas das ciências da cultura para interrogar as formas tradicionais de significação e conhecimento...] (LEFF, 1998, p. 268).

Por isso, é necessário analisar os programas de pesquisa das etnociências. Verificar seus métodos sobre o conhecimento que lançam sobre os saberes culturais. Em outras palavras, não basta reconhecer os propósitos explícitos das etnociências, mas questionar as disciplinas que constituem seu objeto de estudo e desenvolver seus métodos de forma tal que lhes permitam superar o caráter meramente descritivo, para dar explicações consistentes sobre a relação entre 
os sistemas taxonômicos de classificação e as técnicas de uso da natureza: sistemas de idéias, estruturas de pensamento, os códigos de significação, que organizam os valores, das diferentes culturas. A etnobotânica leva a uma reflexão sobre os processos de formação cognitiva (a locomoção, o manuseio, o aprender e a sobrevivência humana forçada a uma interação homem e natureza), que constituem os saberes sobre a natureza a partir da construção do objeto de conhecimento das etnociências.

Isto é, saber a importância e a forma da apropriação da natureza na formação sócio cultural indígena para cada comunidade étnica, pois para cada uma dessas há um significado diferente, com olhares diversos.

A etnobotânica brasileira é originária de várias matrizes culturais que originou um vasto conhecimento de diferentes plantas medicinais. As plantas medicinais são usadas até hoje como matéria-prima para a fabricação de medicamentos. As plantas medicinais têm sido um importante recurso terapêutico desde os primórdios da antigüidade até nossos dias.

O uso terapêutico de plantas é um dos traços mais característicos da espécie humana. Em diversos momentos da história da humanidade, os registros sobre médicos famosos da antigüidade, tais como Hipócrates e outros, as plantas medicinais ocupavam lugar de destaque em suas práticas. A partir de plantas descritas e usadas pelo conhecimento popular, foram descobertos diversos medicamentos usados até hoje pela medicina como por exemplo a copaíba.

Este uso é tão antigo quanto o aparecimento do Homo sapiens, e pode ser encontrado em praticamente todas as civilizações ou grupos culturais conhecidos. Por ser de grande importância cultural ao longo dos séculos, desde a sua descoberta pela humanidade. Torna-se relevante os levantamentos etnobotânicos em especial das espécies dos ecossistemas tropicais, como é o caso da copaíba que contém: as áreas de maior ocorrência do gênero. Os usos tradicionais que diferentes etnias fizeram da mesma e as questões políticas que envolvem sua conservação e manejo. 


\section{DISTRIBUIÇÃo GEOGRÁFICA E CLASSIFICAÇÃo ETNOBOTÂNICA DO GÊNERO COPAÍFERA}

Muitos estudos foram realizados sobre o gênero Copaífera, por inúmeros pesquisadores botânicos. Citar diversas espécies distribuídas em diferentes continentes (Americano e Africano), requer um grande levantamento bibliográfico etnobotânico. A nomenclatura botânica segue, como norma, os nomes mais antigos dados às plantas (JUDD, 1999). Em alguns casos, entretanto, são feitas exceções frente à utilização corrente de outros nomes. Uma destas exceções está nas leguminosas, cujo nome mais antigo é Faba, mas Fabaceae Lindley dá lugar a Leguminosae Juss., na nomenclatura desta que é uma das mais importantes famílias botânicas. A classificação mais moderna da família Leguminosae a divide em três subfamílias: Caesalpinoideae, Mimosoideae e Papilionoideae (ou Faboideae). Por esta classificação, que segue o sistema de Engler, o gênero Copaifera, pertence à família Leguminosae, sub-família Caesalpinoideae, Judd, (1999). Segundo outro sistema de classificação, o de Cronquist, o gênero Copaifera. pertence à família Caesalpiniaceae. A classificação apenas como Fabaceae também é encontrada em alguns livros Harbore (1971), Lewis (1977).

Muitos botânicos e cronistas que estiveram nas Índias Ocidentais e na América no início da colonização descreveram espécies do gênero Copaifera. Descreveram Marcgrave e Piso (1628), os aspectos morfológicos da planta, empregando o termo "Copaiba" sem designar espécies. Mais tarde verificou-se, através dos caracteres descritos pelos dois cronistas, que a espécie estudada foi a Copaifera martii, Dwier, (1951). Foi registrado em detalhes a primeira Copaifera como Copaiva officinalis Jacqui, (1760). Mas, como não possuía o fruto, baseou sua descrição nos aspectos do fruto da espécie estudada por, Marcgrave e Piso (1628). Somente dois anos depois, o cientista Linneus (1630), descreveu corretamente a Copaifera officinalis, assumindo a descrição oficial do gênero Copaifera (LINNAEUS, 1762, apud JUDD, S. W. 1999283 p.).

Foi publicado uma monografia por Hayne em 1825 com oito novas espécies de Copaifer, que apesar de limitações em vista do conhecimento atual, constituiu o mais importante tratado de descrição do gênero e serviu como base para estudos como o de Bentham, no Flora Brasiliensis, realizado durante a expedição com o naturalista (VON, 1870). Os trabalhos mais recentes de descrição de novas espécies de copaíba foram realizados por Harms e Ducke (1967) este último com contribuições de extremo valor sobre as espécies da 
Região Amazônica e do estado do Ceará, e por Dwyer (1954) que realizou um levantamento das espécies americanas.

As copaíbas são árvores nativas da região tropical da América Latina e também da África Ocidental. Na América Latina são encontradas espécies na região que se estende do México ao norte da Argentina. Segundo a última edição do livro, Index Kewensis de Oxford EUA, (1996), o gênero Copaifera possui 72 espécies, sendo que 16 são encontradas no Brasil. Popularmente conhecidas como copaibeiras ou pau d'óleo, as copaíbas são encontradas facilmente nas Regiões Amazônica e Centro-Oeste do Brasil. Entre as espécies mais abundantes, destacam-se: C. officinalis 1. (norte do Amazonas, Roraima, Colombia, Venezuela e San Salvador), C. Guianensis desf. (Guianas), C. reticulata, C. multijuga (Amazônia), C. confertiflora (Piauí), C. langsdorffii desf. (Brasil, Argentina e Paraguay), C. coriacea . (Bahia), C. cearensis (Ceará) Wood, (1940); Perrot, (1993). No Brasil, a espécie C. langsdorfii desf. é particularmente importante por estar distribuída por todo o território (da Amazônia a Santa Catarina, no Nordeste e Centro-Oeste) e por possuir quatro diferentes variedades: C. langsdorfii var. grandifolia, grandiflora (LEITE, 1993). $\mathrm{Na}$ região Amazônica, há uma grande distribuição destas espécies; todas muito semelhantes entre si principalmente, com relação ao tamanho da árvore, sempre muito grande, formando o dossel da floresta na mata virgem. Ocorrem em matas de terra firme solos argilosos e arenosos em todos os Estados. Ocorre desde o médio Tapajós até a Amazônia Ocidental (Amazonas, Acre e Rondônia) e é presente também, nas regiões sul de Roraima, norte de Mato Grosso, Minas Gerais e em pequena quantidade nas demais regiões do Brasil.

$\mathrm{Na}$ África Ocidental são catalogadas 19 espécies na região que inclui Congo, Camarões, Guiné e Angola. Destas, as espécies C. convertifolia, C. demeusii (Copal do Congo), C. coleosperma (Copal da Rodésia), C. conjugata, C. hymenaefolia, $C$. chodatiana $E$ C. fissicuspis, descritas como pertencentes ao gênero copaifera, têm sinônimo nos gêneros guibourtia, gorakia (gorakia conjugata) e cynometra $(C$. fissicuspis). Nesta região são comuns as citações de âmbares (óleo-resinas fossilizadas) provenientes de espécies do gênero copaifera (COUX, 1953, apud JUDD, S. W. ,1999, p.283).

Há, ainda, a citação de uma espécie encontrada na Ilha de Bornéo, Malásia, chamada de Copaifera palustris, que apresenta caracteres bastantes semelhantes aos das espécies africanas e ao gênero Pseudosindora (HOU, 1994). 
O Mapa 01 mostra o mapeamento das regiões onde espécies do gênero Copaifera são encontradas.

\section{MAPA 01 - ÁREAS DE OCORRÊNCIAS DO GÊNERO COPAÍFERA}

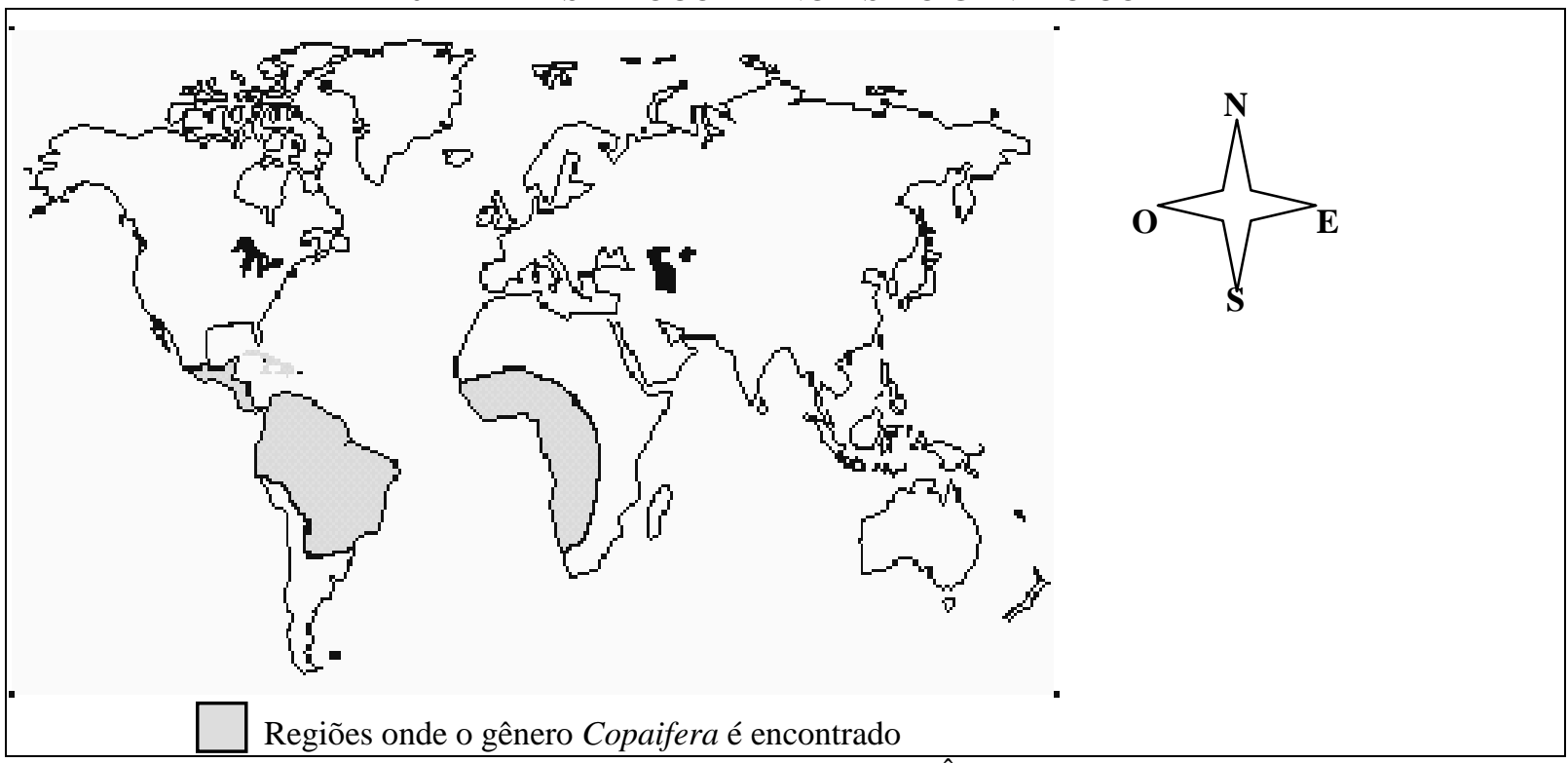

Fonte: VEIGA JR, Valdir F.; PINTO, Ângelo C. (2002)

Ocorrem em matas de terras firmes, solos argilosos e arenosos. Pode ser encontrada em altitude de $50 \mathrm{~m}$ a $1.600 \mathrm{~m}$, precipitação média anula $750 \mathrm{~mm}$ a $2000 \mathrm{~mm}$, com regime pluviométrico uniforme.

FIGURA 01 - A FOLHA DA COPAÍBA

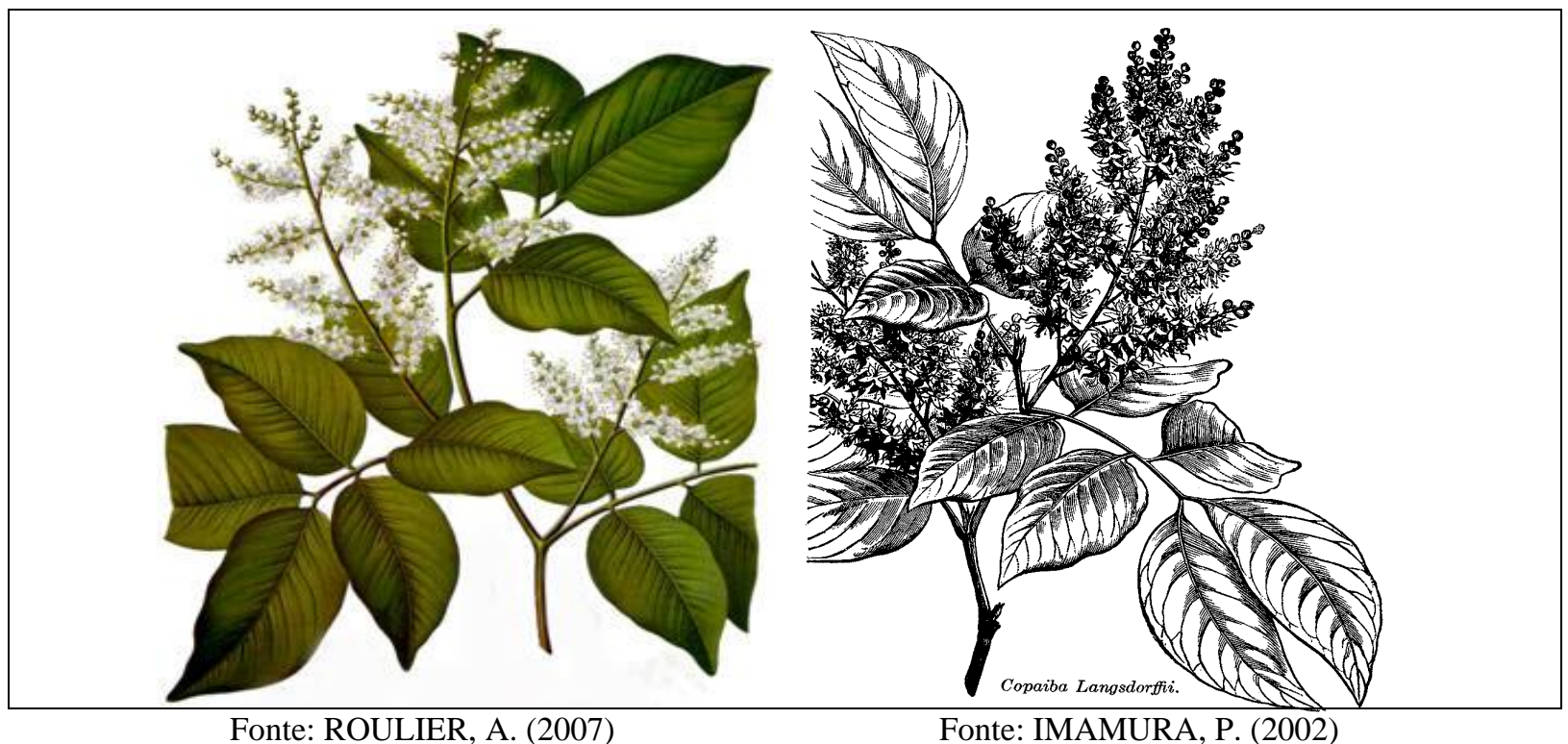


Nas regiões onde ocorre acentuado período seco é rara ou ocasional e cresce em temperaturas ideais de $17^{\circ}$ a $28^{\circ} \mathrm{C}$ de crescimento lento, alcançam de 25 a 40 metros de altura, podendo viver até 400 anos. Tem casca castanha - escura, rugosa e aromática. Apresenta ${ }^{2}$ folhas alternas e ${ }^{3}$ pecioladas simples e compostas, ${ }^{4}$ paripenadas, tendo na base do ${ }^{3}$ pecíolo pequenas ${ }^{5}$ estípulas, ${ }^{6}$ folíolos com 3 a 4 pares opostos, ${ }^{7}$ coriáceos e lisos com ${ }^{8}$ peninérvias e alternas. As folhas são cheias de glândulas contendo óleo resinoso. As folhas quando recém brotadas mostram tonalidades avermelhadas revestindo toda a copa.

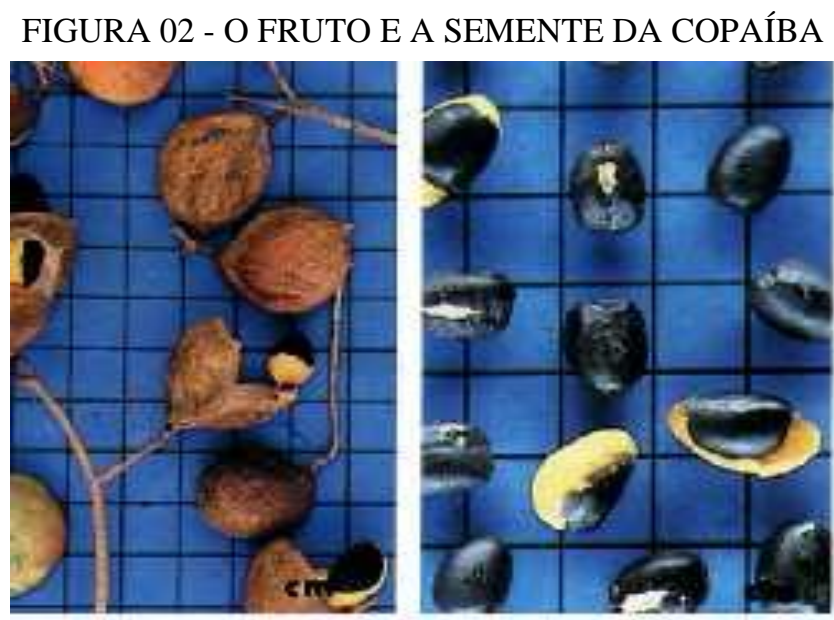

Fonte: HARRI, L. (2000)

As flores são pequenas e brancas, ${ }^{9}$ apétalas, hermafroditas e arranjadas em ${ }^{10}$ penículos axiliares densos também chamam a atenção na paisagem (ALENCAR, 1982). O fruto é uma vagem avermelhada curta ${ }^{11}$ pedunculada, articular, obliqua, comprida, aguda, carnosa,

\footnotetext{
${ }^{2}$ Folhas alternas: sucessão de 02 (Duas) folhas que são mutuamente alternadas.

${ }^{3}$ Pecíolo ou Pecioladas: porção delgada da folha, que prende o limbo à bainha ou ao caule; pé da folha.

${ }^{4}$ Paripenadas: diz-se das folhas compostas, desprovidas de folíolo ímpar terminal, como as da ervilha.

${ }^{5}$ Estípulas: em geral em número par, da base do pecíolo da folha.

${ }^{6}$ Folíolos: cada limbo parcial da folha composta; folha pequena.

${ }^{7}$ Coriáceos: folha com consistência de couro, grossa.

${ }^{8}$ Peninérvias: quando existe uma única nervura primária servindo de origem para as nervuras de ordens superiores.

${ }^{9}$ Apétalas: grupo de plantas dicotiledôneas monoclinas do sistema de Jussileu, cujas flores não têm corola.

${ }^{10}$ Penículos: inflorescência como um cacho, de forma mais ou menos cônica, com o ápice mais estreito e a base larga.

${ }^{11}$ Pedunculada: é a haste de sustentação da flor ou fruto.
} 
${ }^{12}$ bivalves com até $25 \mathrm{~mm}$ de comprimento, contendo uma semente ovóide com ala em forma de saco e quase completamente coberta pelo ${ }^{13}$ arilo.

A casca é fissurada, caule tipo tronco e possui coloração escura, medindo de 0,4 a 4 metros de diâmetro. Sua identificação botânica é realizada, na maioria das vezes, segundo características das flores, como: pêlos nas sépalas, comprimento dos anteros e a condição glaborosa ou não do pistilo, (DWYER, 1951). As características dos frutos são igualmente importantes, mas estes são dificilmente encontrados em coleções botânicas.

FIGURA 03 - FLORAÇÃO E FRUTIFICAÇÃO DA COPAÍBA

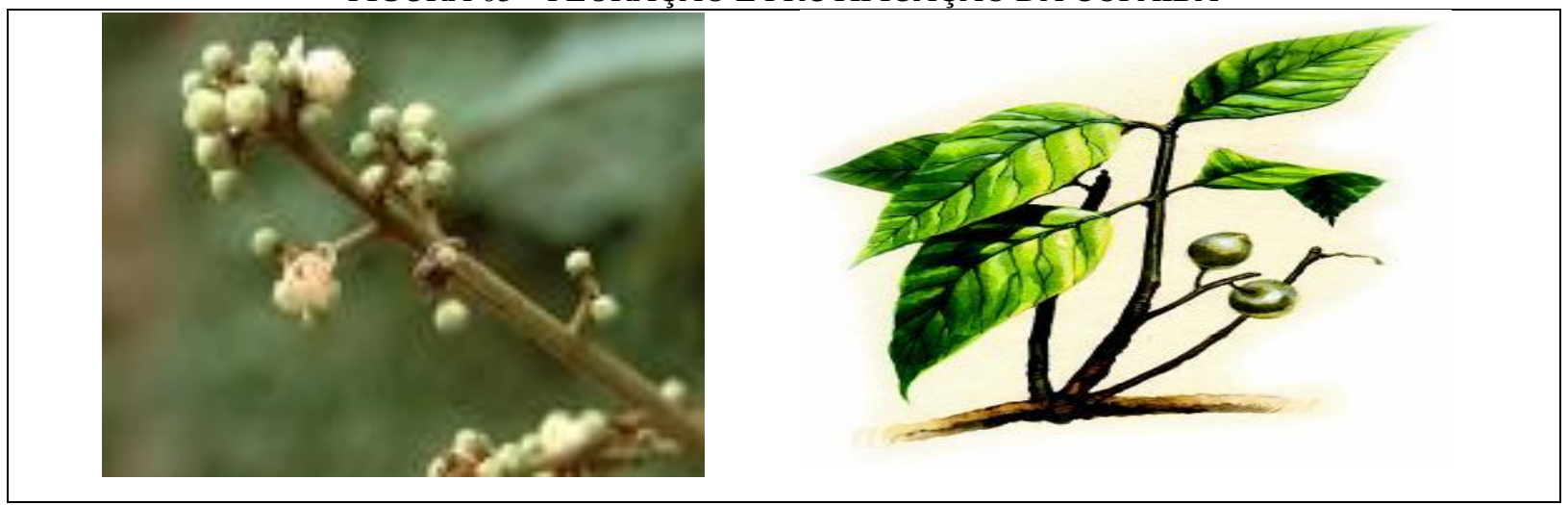

Fonte: www.folhaonline.com.br (2000)

A floração e frutificação das copaíbas ocorrem a partir dos 5 anos de idade, após o plantio em viveiros. A floração (Fig. 03) ocorre entre dezembro e março e a frutificação entre agosto e setembro, com variações dentro destes intervalos, dependendo da região e clima, com ausência de florescimento anual, em algumas regiões, (Santos, 1979).

Algumas espécies, como a Copaifera langsdorfii, são polinizadas no período diurno, de 8:00 às 16:00 horas, com grande participação de Trigona sp e Apis mellifera, (Cristana, 1985) tendo sido encontrados grãos de pólen provenientes de Copaifera em amostras de mel do estado do Ceará, (Barth, 1971, p. 31).

À época da frutificação, as copaíbas são visitadas no período diurno por aves, as quais são as maiores responsáveis pela dispersão de suas sementes, como o tucanuçu (Ramphastos

\footnotetext{
${ }^{12}$ Bivalves: diz-se do fruto ou concha que tem duas valvas. Valva: é cada um dos segmentos de uma fava deiscente, ou seja, é a abertura espontânea das válvulas ou poros de um órgão vegetal de propagação, para a saída do seu conteúdo.

${ }^{13}$ Arilo: tegumento de certas sementes ou apêndice do funículo que cobre a micrópila depois da fecundação do óvulo.
} 
toco), a galha-do-campo (Cyanocorax cristatellus) e o sabiá, que engolem o ${ }^{13}$ arilo e regorgitam a semente (CARVALHO, 1984).

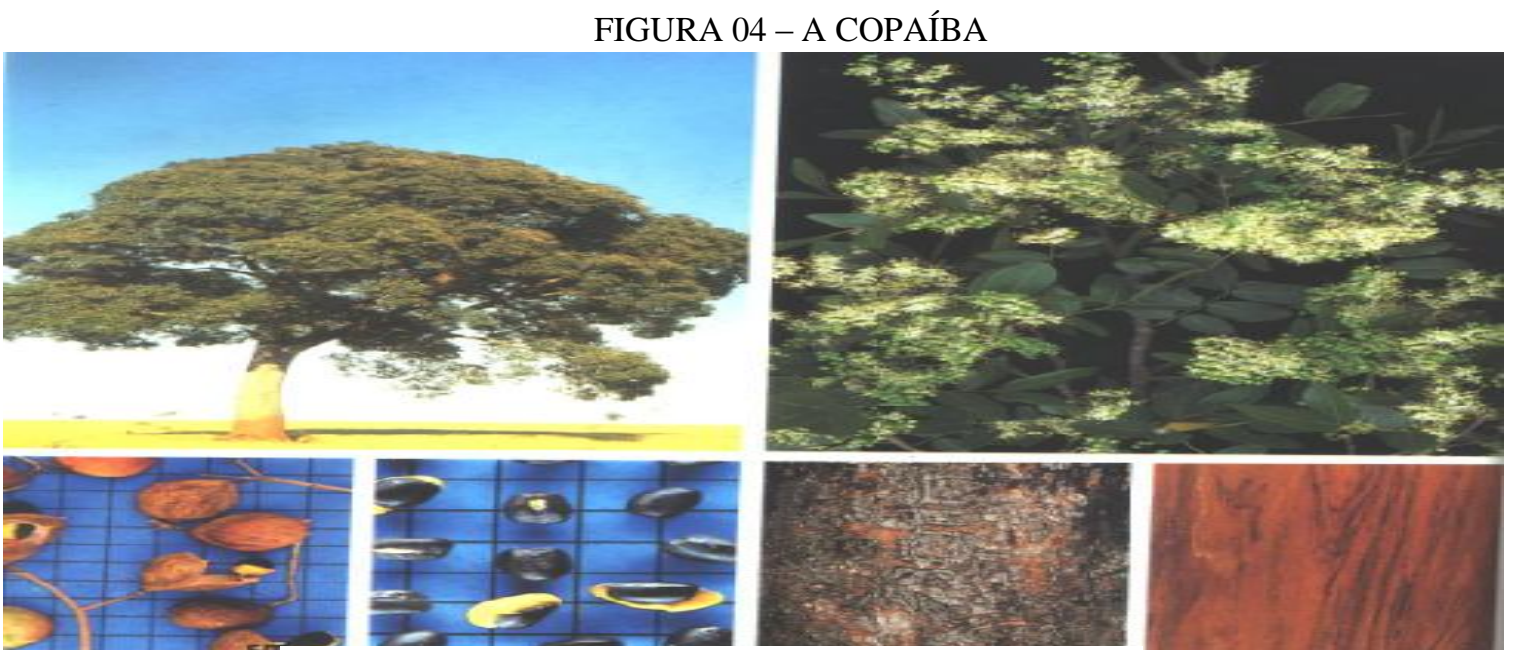

Fonte: HARRI, L. (2000)

No período noturno, as copaíbas são ponto de encontro de diversos mamíferos, como os macacos mono-carvoeiros (Cebus apella nigritus), observados por Beritti (2000) no Parque Nacional de Iguaçu, na Argentina, e que utilizam sua copa como ponto de descanso noturno, como pequenos roedores que apreciam os frutos e são atraídos pelo cheiro de ${ }^{14}$ cumarina presente nas sementes maduras e, por último, os indígenas, no norte do país, que apreciam a carne destes pequenos roedores e utilizam as copaíbas como local de espera de caça.

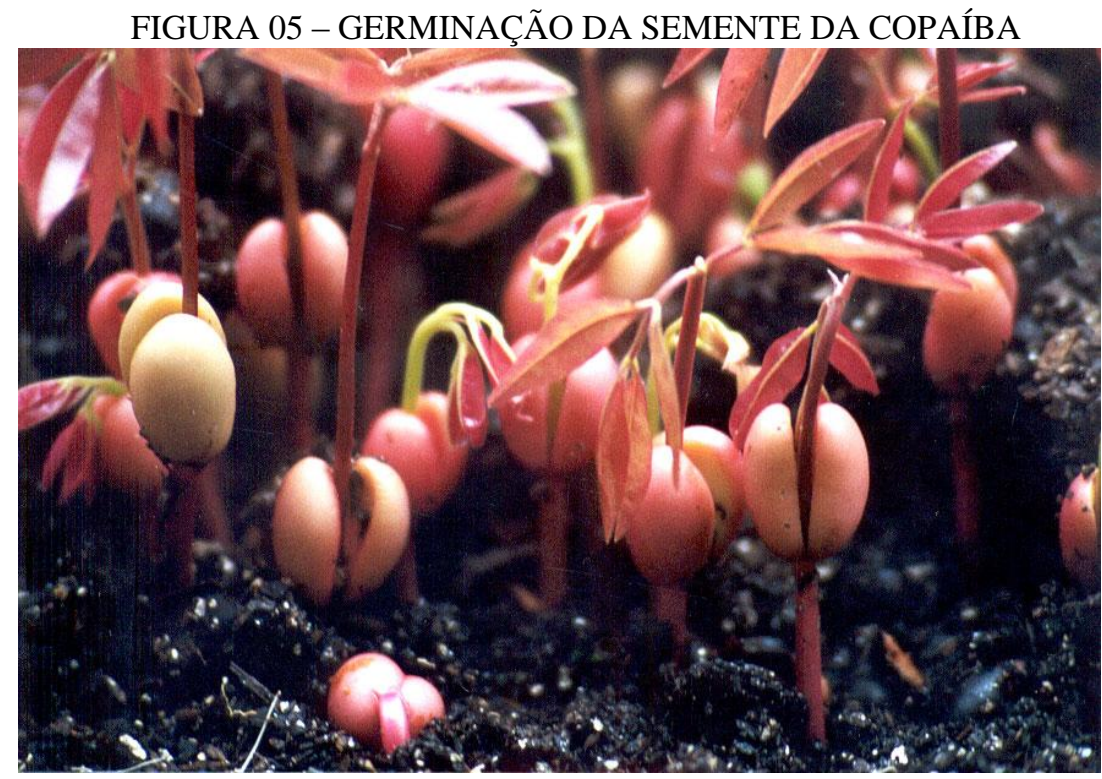

Fonte: IMAMURA, P. (2002)

\footnotetext{
${ }^{14}$ Cumarina: é uma polpa amarelada, que envolve a semente da copaíba.
} 
A biologia das sementes de C. langsdorfii foi estudada por diversos pesquisadores que abordaram desde sua morfologia e anatomia (CRISTANA, 1988), passando pela sua conservação (IRA, 1982) e maturação (BARBOSA, 1982), até a germinação (BORGES, 1979).

\section{1 - DA EXTRAÇÃO DO ÓLEO, HISTÓRIAS E RITOS}

A comunicação oral é o principal modo pelo qual o conhecimento é perpetuado. Isto acontece normalmente em sociedades rurais ou indígenas, nas quais o aprendizado é feito pela socialização no interior do próprio grupo doméstico e de parentesco. Uma das origens do sistema brasileiro de plantas medicinais deriva das características peculiares da flora da região Amazônica associada à absorção de conhecimentos indígenas e ${ }^{15}$ quilombolas pelo caboclo. Ele também decorre do isolamento cultural da Amazônia, que levou ao uso de ervas específicas da região uma linguagem própria. É o caso da planta como Copaíba.

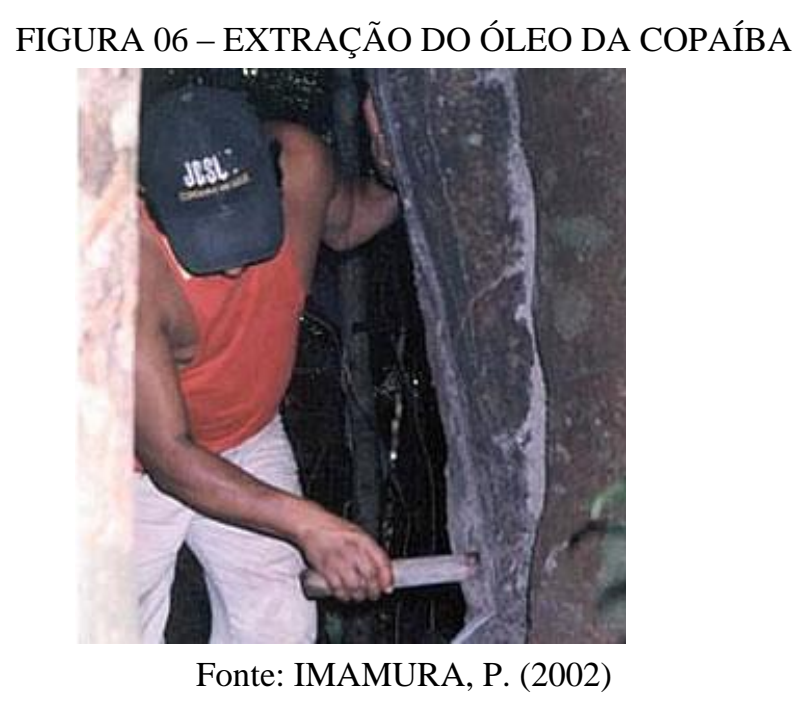

São vários os métodos relatados para a retirada do óleo de copaíba e da madeira utilizada para carvão e indústria de móveis. Antigamente, obtinha-se o óleo através de cortes a machado no tronco, o que inutilizava a árvore (LE CONTE, 1927).

\footnotetext{
${ }^{15}$ Quilombolas: escravos ou escravas refugiados em quilombos.
} 
Por ser um corte profundo, ocasionava a queda da árvore em função dos fungos e cupins. De acordo com (OLIVEIRA e MATTA, 1905 apud JUDD, 1999, p.283) também se utilizava a incisão em V, colocando-se abaixo vasos apropriados para receber o óleo, à semelhança da extração de borracha, é o chamado método do arrocho, que consiste em selar o tronco, abaixo das incisões, com ${ }^{16}$ embiras e cipós e coletar o óleo da árvore até o seu esgotamento, provocando sua morte, são métodos há muito tempo abandonados. A retirada por meio de bomba de sucção também é descrita, porém pouco difundida.

A única prática de coleta não agressiva é aquela realizada através de uma incisão com trado a cerca de 1 metro de altura do tronco (ALENCAR, 1982). Terminada a coleta, o orifício é vedado com argila para impedir a infestação da árvore por fungos ou cupins.

Um dos aspectos interessantes da copaíba é o procedimento da retirada do óleo utilizado pelos indígenas e ainda observado no interior do Brasil. Muitos destes procedimentos são considerados místicos pela ciência de hoje, embora tenham sido adquiridos pelos indígenas através da experimentação ${ }^{17}$ empírica durante milhares de anos. Vários cronistas, que estiveram na América Latina em regiões tão diferentes como a bacia amazônica e do Prata e o nordeste brasileiro relatam a utilização das mesmas técnicas por índios separados por milhares de quilômetros.

O cronista João Ferreira Rosa (1694) em seu Tratado Único da Constituição Pestilencial relatava: "Neste pau, nas noites de lua cheia, quando os frutos estão maduros, se faz golpe até a medula, [...], correr óleo em grande quantidade.” Ainda hoje os mesmos procedimentos são seguidos pelos indígenas.

Segundo relatos dos primeiros colonizadores a origem do nome copaíba parece vir do tupi cupa-yba, a árvore de depósito, ou que tem jazida, em alusão clara ao óleo que guarda em seu interior. Chamado de copaíva ou copahu pelos indígenas (do tupi: Kupa'iwa lery, (1557) e Kupa'ü Grande, (1998), respectivamente), e cupay, na Argentina e no Paraguai (guarani), o óleo de copaíba e suas propriedades medicinais eram bastante difundidos entre os índios latino-americanos à época que aqui chegaram os primeiros exploradores europeus no século XVI (MARTIUS, 1854).

\footnotetext{
${ }^{16}$ Embiras: fibra de alguns vegetais que fornece matéria-prima para cordas e estopas.

${ }^{17}$ Empírica: baseado na experiência, ou seja, são os conhecimentos práticos devidos meramente à experiência.
} 
Tudo indica, que tais conhecimentos vieram da observação do comportamento de certos animais que, quando feridos, esfregavam-se nos troncos das copaibeiras para cicatrizarem suas feridas, como observou o holandês Gaspar Barléu (SALVADOR, 1975).

As propriedades do óleo tão apreciado pelos índios, que o usavam principalmente como cicatrizante e antiinflamatório, fizeram com que a copaíba fosse uma das primeiras espécies a serem descritas pelos cronistas portugueses (MARCGRAVE, 1942), (CARRARA, 1996). A primeira citação sobre o óleo talvez tenha sido em uma carta de Petrus Martius ao Papa Leão X, publicada em Estrasburgo em 1534, em que a droga utilizada pelos índios era chamada de “18 Copei”.

Uma publicação da mesma época do padre Jesuíta José Acosta, "De Natura Novi Orbis", foi traduzida do latim para o francês em 1606. Na tradução portuguesa de José Maffeu, intitulada "História Natural e Moral das Índias", encontra-se o seguinte trecho Acosta:

... o ${ }^{19}$ bálsamo é celebrado com razão por seu excelente odor, e muito maior efeito para curar feridas, e outros diversos remédios para enfermidades, que nele se experimentam [...] nos tempos antigos os índios apreciavam em muito o ${ }^{19}$ bálsamo, com ele os índios curavam suas feridas e que delas aprenderam os 253 espanhóis. (COSTA, 1792, p. 253)

O jesuíta José de Anchieta, em sua longa carta ao Padre Geral, datada de São Vicente, em fins de 1560, comenta as utilidades do óleo de copaíba (RODRIGUES, 1934): “exala um cheiro muito forte porém suavíssimo e é ótimo para curar feridas, de tal maneira que em pouco tempo nem mesmo sinal fica das cicatrizes.

A descoberta da terapêutica indígena permitiu que os primeiros médicos que trabalharam no Brasil contornassem parcialmente a escassez dos remédios empregados na Europa, cujo suprimento à Colônia era intermitente.

As práticas indígenas eram tão difundidas, que os viajantes sempre se abasteciam destes medicamentos, “comprovadamente eficientes", antes de excursões por regiões pouco conhecidas (CARRARA, 1996).

\footnotetext{
${ }^{18}$ Copei: é o nome que originou Copaíba, na língua Tupi-Guarani.

${ }^{19}$ Bálsamo: resina aromática ressumada ou extraída de alguns vegetais. É uma designação de numerosas árvores leguminosas.
} 
São muitas as denominações que recebem as copaibeiras nas diversas regiões da América Latina onde são utilizados os seus derivados. Na Região Amazônica o uso das propriedades da copaíba é tão extenso, que a copaíba destaca-se como a planta medicinal mais utilizada e conhecida pela população. Fora da Região Amazônica a espécie mais comum é a Copaifera langsdorfii, conhecida por diversos nomes segundo Braga, 1960.

\begin{abstract}
As várias regiões onde é encontrada, a saber: óleo-de-copaíba (RJ, SP, ES), óleopardo, óleo vermelho (BA, RJ, SP), bálsamo, caobi, capaíba, capaúba (MS), coopaíba (MG), copaí, copaibeira, copaibeira-de-minas, copaúba (SP), copaíbapreta, copaíba-de-várzea, copaíba-vermelha, óleo- amarelo, óleo-capaíba (BA, MG), copaúva, cupaúva, cupiúva, cupiuba, oleiro, óleo (MG, PR), pau-óleo (PR), pauóleo-de-copaíba, pau-óleo-do-sertão (BA), pau-d'óleo, podoi (PI, CE), e copaibeira nos demais estados do sul do país (Braga, 1960, p. 401).
\end{abstract}

Segundo João Ferreira Rosa em 1694 convivendo com os tapuias, foi um dos cronistas que melhor descreveu as utilizações do óleo de copaíba e a forma como deveria ser aplicado.

As aplicações a quente e em compressas em partes externas só são encontradas em relatos mais antigos e hoje abandonadas da terapêutica. Rosa cita ainda a utilização do óleo em massagens na cabeça para curar paralisias, dores de cabeça e convulsões. O chá das cascas e sementes da Copaifera também é indicado para diversos males, especialmente na Venezuela e Colômbia, onde são utilizados como anti-hemorroidal e purgativo (MATOS, 1997), (FONSECA, 1939) e na Amazônia Brasileira é indicado no tratamento de moléstias pulmonares e asma. Na África Ocidental (Camarões) encontra-se uma utilização medicinal para um óleo de copaíba específico, Copaifera religiosa, indicado no tratamento da sífilis e blenorragia (MALLART, 1969). Ao norte do Brasil, o caboclo faz amplo uso do óleo de copaíba como produto medicinal e também como combustível na iluminação pública. A copaíba também se insere em contexto ritualísticos como é o caso do uso em religiões afrobrasileira, entre elas o cadomblé e a umbanda. No Brasil, utiliza-se as folhas da copaíba na maioria das vezes nos rituais sagrados, como nos banhos e sacudimentos, procedimentos utilizados durante as cerimônias religiosas. Já o óleo da copaíba é de grande importância nos rituais sagrados dos Vodus. Os objetos utilizados nos rituais são envolvidos no óleo mantendo com isso seus costumes africanos, não só nos cultos de umbanda e candomblé, mas em toda cultura religiosa do Brasil e das Américas. Na América Central, região denominada Antilhas, onde há uma grande influência de rituais afros, a copaíba recebe o nome de kiroro pelas santeiras cubanas. As santeiras utilizavam as folhas e óleo de copaíba, nos rituais de 
benzimento e na cura de males. Rituais até hoje difundida entre os cubanos e regiões próximas. Segundo os jesuítas, em seus relatos os saberes dos nossos antepassados, os indígenas e os caboclos, utilizavam o óleo de copaíba para uso medicinal e pós-guerras.

Já os índios brasileiros quando retornavam de suas guerras sangrentas intertribais, costumavam repousar seus feridos em esteiras sustentadas por varas, sobre um braseiro com seus corpos untados com este óleo, pois acreditavam no seu poder cicatrizante. (BARROS, 2007)

As medicações com óleo de copaíba confirmam a sabedoria popular e o conhecimento dos indígenas, africanos e caboclos que posteriormente foi apropriado pelos colonizadores portugueses e espanhóis. Portanto, no início do século XVIII, diante da escassez de medicamentos na Europa em função das guerras ${ }^{20}$ prussianas e outras, o óleo de copaíba tornou-se um importante substituto medicinal, na cultura européia da época.

\section{CONCLUSÃO}

Algumas plantas medicinais consideradas, como a copaíba, são restritas ao uso popular e à abordagem terapêutica desde o salto tecnológico da indústria farmacêutica. Portanto, os esforços para a construção do conhecimento, baseado nos valores etnoculturais, a partir do conhecimento etnobotânico tradicional.

Desde o uso da Copaíba, na medicina alternativa pelos primitivos e colonizadores até a extração do óleo, com essências farmacológicas. Assim sendo, independentes dos monopólios internacionais das indústrias farmacêuticas. Para tanto devemos valorizar, estudar, validar e utilizar terapeuticamente nossas espécies, antes que outros o façam, como já vem ocorrendo através das leis de patentes e da biopirataria.

\section{REFERÊNCIAS BIBLIOGRÁFICAS}

ALENCAR, J. C.; Acta Amazonica., 1982, 12, 75 p., apud VEIGA Jr., Valdir F.; PINTO, Angelo C.; Química Nova, Vol 25, No 02, Instituto de Química, UFRJ, Ilha do Fundão - RJ, Figura 01, 2002, 274 p.

\footnotetext{
${ }^{20}$ Prussianas: oriundo da Prúscia.
} 
BARBOSA, J. M.; AGUIAR, I. B.; SANTOS, S. R. G.; 2 o Congresso Nacional sobre

Essências Nativas, Brasília, Brasil, 1992.

BARRERA, A .; La Etnobotânica: três Puntos de Vista e uma Perspectiva; Inst. Delegación sobre Recursos Biótico: Xalapa, México, 1979, 19-25 p., apud PASAI, Maria Corette.; Estudo EtnoBotânico, Vol 19 n. ${ }^{\circ}$ 2, São Paulo, 2005; UFMT, Instituto de Biociências, Depto. De Botânica e Ecologia: Cuiabá, MT.

BARROS, J. F. P. ; NAPOLEÃO, E., Ewé òrìsà :uso litúrgico e terapêutico dos vegetais nas casas de candoblé jêje-nagô, Rio de Janeiro - RJ, Bertrand Brasil $3^{\mathrm{a}}$ Ed., 2007.

BARTH, O. M.; Rev. Brasil. Biol. 1971, 31, 431 p., apud VEIGA Jr., Valdir F.; PINTO, Angelo C.; Química Nova, Vol 25, Nº 02, Instituto de Química, UFRJ, Ilha do Fundão - RJ, Figura 01, 2002, 274 p.

BORGES, E. E. L.; BORGES, C. G.; Rev. Bras. Sem. 1979, 1, 45 p., apud VEIGA Jr., Valdir F.; PINTO, Angelo C.; Química Nova, Vol 25, Nº2, Instituto de Química, UFRJ, Ilha do Fundão - RJ, Figura 01, 2002, 274 p.

BRAGA, R.; Plantas do Nordeste, especialmente do Ceará; $3^{\mathrm{a}}$ ed., Fortaleza, 1960, 401 p.

CABAllerO, J.; La Etnobotânica: três Puntos de Vista e uma Perspectiva; Inst. Delegación sobre Recursos Biótico: Xalapa, México, 1979, 27-30 p., apud PASAI, Maria Corette., Estudo EtnoBotânico, Vol 19 n. ${ }^{\circ}$ 2, São Paulo, 2005; UFMT, Instituto de Biociências, Depto. De Botânica e Ecologia: Cuiabá, MT.

CARRARA JR., E.; MEIRELLES, H.; A Indústria Química e o Desenvolvimento do Brasil 1500-1889; Ed. Metalivros, São Paulo - SP, 1996, 115 p.

CARVALHO, P. E. R.; Espécies florestais brasileiras; recomendações silviculturais, potencialidades e uso de madeira; EMBRAPA/CNPF, Brasília, 1994, 640 p.

COSTA, J.; História Natural e Moral das Índias; Madrid, 1792, 253 p.

DUCKE, A.; HARMS; An. Acad. Brasil. Ciências 1967, 30, 327 p., apud VEIGA Jr., Valdir F.; PINTO, Angelo C.; Química Nova, Vol 25, No 02, Instituto de Química, UFRJ, Ilha do Fundão - RJ, Figura 01, 2002, 274 p.

DWYER, J. D.; Brittonia 1951, 7, 143 p., apud VEIGA Jr., Valdir F.; PINTO, Angelo C.; Química Nova, Vol 25, No 02, Instituto de Química, UFRJ, Ilha do Fundão - RJ, Figura 01, 2002, 274 p.

DWYER, J. D.; Bull. Torrey Bot. Club 1954, 81, 179 p., apud VEIGA Jr., Valdir F.; PINTO, Angelo C.; Química Nova, Vol 25, Nº 02, Instituto de Química, UFRJ, Ilha do Fundão - RJ, Figura 01, 2002, 274 p.

FONSECA, E. T.; Revista da Flora Medicinal 1939, 6, 161 p., apud VEIGA Jr., Valdir F.; PINTO, Angelo C.; Química Nova, Vol 25, No 02, Instituto de Química, UFRJ, Ilha do Fundão - RJ, Figura 01, 2002, 274 p.

HARBONE, J.B.; BOULTER, D.; TURNER, B.L.; Chemotaxonomy of the Leguminosae; Academic Press: London, 1971, 1 p. 
HAYNE; Arzneig 1825, 10 e 16 p., apud VEIGA Jr., Valdir F.; PINTO, Angelo C.; Química Nova, Vol 25, N 02, Instituto de Química, UFRJ, Ilha do Fundão - RJ, Figura 01, 2002, 274 p.

HOU, D.; Blumea 1994, 38, 313 p., apud VEIGA Jr., Valdir F.; PINTO, Angelo C.; Química Nova, Vol 25, Nº 02, Instituto de Química, UFRJ, Ilha do Fundão - RJ, Figura 01, 2002, 274 p.

IMAMURA, P. M. Em Organic Synthesis in Brazil: A Overview, Ed. USP:

São Paulo, 1992, 62 p.

INDEX KEWENSIS, suppl. XX; Claredon Press: Oxford, 1996, apud VEIGA Jr., Valdir F.; PINTO, Angelo C.; Química Nova, Vol 25, No 02, Instituto de Química, UFRJ, Ilha do Fundão - RJ, Figura 01, 2002, 274 p.

JACQUI; Enum. Pl. Carib. 1760, 65 p., apud VEIGA Jr., Valdir F.; PINTO, Angelo C.; Química Nova, Vol 25, No 02, Instituto de Química, UFRJ, Ilha do Fundão - RJ, Figura 01, 2002, 274 p.

JUDD, S. W., Sistemática das Plantas - Uma Aproximação Filogenética, Sunderland - EUA, Ed. Sinauer, 1999, 283 p.

LE CONTE, P.; Apontamentos sobre as sementes oleaginosas; Museu Comercial do Pará, $3 \mathrm{a}$. ed., Belém, 1927, 47 p.

LEITE, A. M. C.; LLERAS, E.; Acta Bot. Bras., Rio de Janeiro - RJ, Ed. Scielo, 1993, 7 p., 61.

LEFF, E., O saber ambiental, Petrópolis - RJ, Ed. Vozes, 2001, 265 e 268 p.

LEWIS, W. H.; ELVIN-LEWIS, M. P. F.; Medical Botany; John Wiley and Sons, New York, 1977, $293 \mathrm{p}$.

LINNEUS; Sp. Pl. 1762, 557 p., apud JUDD, S. W., Sistemática das Plantas - Uma Aproximação Filogenética, Sunderland - EUA, Ed. Sinauer, 1999, 283 p., apud apud VEIGA Jr., Valdir F.; PINTO, Angelo C.; Química Nova, Vol 25, Nº 02, Instituto de Química, UFRJ, Ilha do Fundão - RJ, Figura 01, 2002, 274 p.

HARRI, L.; RENZI, H, Árvores Brasileiras, Nova Odessa - SP, Vol. 1, $3^{\text {a }}$ Ed. Plantarum, 2000, 146 p.

MALLART-GUIMERA, L.; Le thème de 1 árbre dans les contes africains; Selaf 16, Paris, 1969.

MARCGRAVE, J.; História Natural do Brasil, Imprensa Oficial do Estado; São Paulo - SP, $1942,130 \mathrm{p}$.

MATTA, A. A.; Flora Medica Braziliense; Imprensa Oficial: Manaus, 1913, 318 p., apud JUDD, S. W., Sistemática das Plantas - Uma Aproximação Filogenética, Sunderland - EUA, Ed. Sinauer, 1999, 283 p.

MATOS, F. J. A.; O Formulário Fitoterápico do Professor Dias da Rocha, 2a ed.; Edições UFC: Fortaleza, 1997, 113 p. 
OLIVEIRA, F. M. M.; Estudos de Matéria Médica Vegetal; Escola Typographica Salesiana: São Paulo, 1905, 114 p., apud JUDD, S. W., Sistemática das Plantas - Uma Aproximação Filogenética, Sunderland - EUA, Ed. Sinauer, 1999, 283 p.

PERROT, E.; Matières premières usuelles du Règne végétal; Tomo II, Masson et Cie. Éditeurs: Paris, 1994, 2344 p.

PISO, G.; História Natural e Médica da Índia Ocidental; MEC, Rio de Janeiro, 1957, 270 p.

RODRIGUES, L.; Anchieta e a medicina; Edições Apollo: Belo Horizonte, 1934, 361 p.

ROSA, J. F.; Tratado Único da Constituição Pestilencial de Pernambuco;

Lisboa, 1694, 37 p., apud VEIGA Jr., Valdir F.; PINTO, Angelo C.; Química Nova, Vol 25, No 02, Instituto de Química, UFRJ, Ilha do Fundão - RJ, Figura 01, 2002, 274 p.

SALVADOR, V.; História do Brasil: 1500-1627, $\sigma^{a}$ Ed.; Melhoramentos, São Paulo - SP, 1975, 65 p.

SANTOS, N.; Rodriguesia 1979, 31, 223 p., apud VEIGA Jr., Valdir F.; PINTO, Angelo C.; Química Nova, Vol 25, No 02, Instituto de Química, UFRJ, Ilha do Fundão - RJ, Figura 01, 2002, 274 p.

SHIVA, V., Monocultura da Mente, São Paulo - SP, Ed. Gaia, 2002.

VEIGA Jr., Valdir F.; PINTO, Angelo C.; Química Nova, Vol 25, $\mathrm{N}^{\mathrm{o}}$ 02, Instituto de Química, UFRJ, Ilha do Fundão - RJ, Figura 01, 2002, 274 p.

VON MARTIUS, C. F. P.; Systema de Materia Medica Vegetal; Ed. Eduardo \& Henrique Laemmert, Rio de Janeiro - RJ, 1854, 206 p., apud JUDD, 1999.

WOOD, H. C.; LAWALL, C. H.; YOUNJKEN, H. W.; OSOL, A.; GRIFFITH, I.;

GERSHENFELD, L.; The dispensatory of the United States of America, J. B. Lippincott Company: London, 22a ed., 1940, 369 p.

http://www.folhaonline.com.br (2000)

(Recebido em outubro/08. Aceito em maio/09) 